\title{
Management of lower limb open fractures: An unresolved challenge
}

\author{
Abeysekera WYM, Pinto MN, Suran M, Mohan BMP \\ Accident and Orthopaedic Service, National Hospital, Colombo, Sri Lanka.
}

Correspondence: Dr. WYM Abeysekera

e-mail: yohan.abeysekera@yahoo.com

\section{Introduction}

Management of lower limb open fractures is one of the major orthopaedic challenges still subjected to many arguments. Infection is the most devastating complication of all open fractures, which needs special attention. Failure of such attention may lead to a significant morbidity causing delayed union, non-union, multiple additional surgeries or even amputation (1).

Many decades back Gustilo and Anderson in their landmark study expressed clearly the increased risk of infection with the increase in severity of the fracture. It was $2 \%$ in type I fractures, $2 \%$ to $15 \%$ in type II fractures, and $5 \%$ to $50 \%$ in type III fractures (2). In a recent study similar results emerged as risk of infection $1.4 \%, 3.6 \%$ and $22.7 \%$ for type I, II and III fractures, respectively (3).

Factors leading to infections include incomplete excision of poorly vascularised tissue, inadequate haemostasis and haematoma evacuation, insufficient drainage of wound discharges, devascularization of primarily viable tissue, large metallic fixation devices implanted under poorly vascularised tissue, wound closure under tension and failure to recognize compartment syndrome (4). Many of these factors can be avoided by following a standard management procedure in handling open fractures.

In the standards set by BPRAS/BOA (The British Association of Plastic Reconstructive and Aesthetic surgeons and The British Orthopedic Association) in the management of lower limb open fractures early administration of appropriate antibiotics, thorough surgical debridement, proper skeletal stabilization and early soft tissue cover have been considered as the main steps (5).
Except in a tertiary care setup with adequate orthopedic staff and facilities the initial wound handling of an open fracture is done by General surgical teams. As the first debridement is the most important prognostic factor of open fractures the knowledge on proper handling of lower limb open fracture is an equally important topic for General surgery as well.

\section{Emergency Management}

Advanced Trauma Life Support Protocol would be the guide for initial management of lower limb open fractures. Resuscitation and stabilization of the patient should be done following a rapid accurate assessment of the condition of the patient. If there is evolving or already established limb threatening condition (e.g. vascular injury) immediate steps should be taken to correct it or transfer the patient to a better facility. It is appropriate inform the receiving hospital beforehand.

In the emergency department the open fracture should be handled only for the removal of gross contaminants, photography and radiography related to injury. Except for saline soaked dressing nothing should be used to cover the wound (5). Limb splintage is the ideal method for immobilization of the limb. Antibiotic and anti-tetanus prophylaxis can be started at the same time.

\section{Antibiotic prophylaxis}

In the absence of prophylactic antibiotics the risk of infection would be nearly $20 \%$ in open fractures (6). Thus many studies have recognized the value of early prophylactic antibiotics including a recent 
Cochrane group study which declared a reduction of infection rate from $13 \%$ to $5 \%$ in a comparison of prophylactic antibiotics vs placebos in the management of open fractures (7).

The BAPRAS/BOA recommendations have stressed the value of early administration of antibiotics and the importance of administration them within the first 3 hours (5). This 3 hour rule emerged as a result of a study which recognized the $3 \%$ increase in the risk of infection when the administration of prophylactic antibiotics delayed beyond 3 hours (8).

Many authors have reported a higher prevalence of Staphylococcus aureus in surgical site infections in open fractures $(9,10,11)$, and some of them detected a significantly high rate of MRSA (11). In order to cover Gram positive infections, the most widely used drug of choice is the first generation cephalosporin. Some authors including recently published East guidelines (12) have suggested an additional Gram negative cover for severe open fractures $(4,6,13,14)$.

Based on evidence, British recommend Intravenous first generation cephalosporin or Co-Amoxiclav as the first line antibiotic for lower limb open fracture management. Further they suggest gentamicin single dose prior to wound debridement to cover the Gram negative organisms, combined with a single dose of vancomycin or teicoplanin at the time of skeletal stabilization or definitive soft tissue cover. In an allergy to penicillin is reported, clindamycin would be the drug of choice (5).

In another evidence-based protocol clindamycin was used as the drug of choice in cases with grossly contaminated wounds eg: farmyard/sewage, (1) but some have considered metranidazole in agricultural infections (4). Due to inadequate evidence, none of the studies have recommended fluroquinolones (e.g. ciprofloxacin) for the management of open fractures (3).

Some authors feel that antibiotic cover needs to be altered based on the type of contamination e.g. additional anaerobic cover in a strong soil contamination or a cover for the possible nosocomial infections during treatment in a hospital setup especially Gustillo type III open fractures (14).

Mauffrey et al. suggested that even though prophylactic antibiotics are commenced in the emergency room based on the external appearance and radiological findings, the real assessment of the injury would be possible only during the first debridement, therefore the final antibiotic prophylaxis protocol should not be based on the initial open wound size but rather should be chronologically based, following an algorithm with a prophylaxis tailored to the surgical management of the open wound, the fracture, the associated bone, and vascular and muscle injury (1).

Controversy still remains about the duration of antibiotics. In a recent RCT comparing prophylaxis with IV cephalosporin for 24 hours vs. 5 days showed that there is no added benefit of prolonged prophylaxis for more than 24 hours, (15) but many authors suggest antibiotics for 3-5 days. $(4,5,6,14,16)$ Based on the current evidence British recommendations describe the continuation of antibiotic prophylaxis for $24-48$ hours for type I fractures and 72 hours or until the definitive soft tissue closure or whichever is shorter for type II and III fractures (5).

\section{Surgical debridement}

The rule of mandatory wound debridement within six hours derived as a result of studies in preantibiotic era which showed infection threshold of $10^{5}$ organisms per gram of tissue reached in at an average of $5.17 \mathrm{~h}$ (17). Subsequent clinical studies also have supported the importance of early debridement including Gustillo and Anderson $(2,17,18)$. Some studies, however, have shown poor outcome resulted due to the initial surgical debridement performed in an unnecessary urgency by inexperienced non-orthopedic surgical teams under sub-optimal surgical environments $(1,3)$. Thorough debridement by an experienced surgeon appears to be better than an inadequate performance in suboptimal conditions within 6 hours (19). Thus the initial debridement should be performed by senior plastic and orthopedic surgeons working together on scheduled trauma operating lists within normal working hours and within 24hours of the injury unless there is gross contamination eg: marine, agricultural or sewage contamination, compartment syndrome, vascular injury and multiple injuries (5). 


\section{Technique of Debridement and Irrigation}

Careful Surgical debridement and thorough irrigation are the main pillars of a successful management of an open fracture. These steps would make the management of open fractures different from just another wound debridement (Table). Removal of contaminating debri would reduce the risk acute and chronic infection of the wound. Irrigation will reduce the risk by diluting the content of organisms in the lesion based on the concept of "Dilution is the solution to pollution".

For the irrigation, high pressure pulse lavage is discouraged due to the evidence which suggests possibility of inoculation of dirt and bacteria to the soft tissues and bone, with micro architecture damage to the tissues. Thus low or medium pressure lavage would be the ideal $(4,5,20)$.

Ideal solution to be used in irrigation is still unclear and in many instances $0.9 \%$ saline solution is used. AO suggests it is better to use optimally balanced salt solution, such as Ringer-lactate (4). Addition of antiseptics or antibiotics to the lavage fluid has not been effective (5). The volume of lavage solution has not been addressed in BAPRAS/BOA guidelines. But some institutions still use the popular protocol of 3, 6, 9 Liters of normal saline for type I to III fractures, respectively (21).

Table: Technique of wound proper debridement in The Standards for the Management of Open. Fractures of the Lower Limb 2009 by The British Association of Plastic Reconstructive and Aesthetic surgeons and The British Orthopedic Association

- Limb washed with a soapy solution and a tourniquet is applied.

- Limb 'prepped' with an alcoholic chlorhexidine solution, avoiding contact of the antiseptic with the open wound and pooling under the tourniquet.

- Soft tissue debridement/excision (excision of all devitalized tissue - except neurovascular bundles)

- Visualization of the deeper structures, by wound extensions along the fasciotomy lines

- Systematic assessment of tissues from superficial to deep and periphery to the centre

- Classify the injury

- $\quad$ Remove non-viable skin, fat, muscle and bone

- Careful surgical delivery of bone ends through the wound extension for circumferential assessment.

- Fracture ends and larger fragments which fail to demonstrate signs of viability are removed.

- Major articular fragments are preserved as long as they can be reduced and fixed with absolute stability.

- Definitive reconstruction planned jointly by the senior members of the orthopaedic and plastic surgical teams

- If definitive skeletal and soft tissue reconstruction is not to be undertaken in a single stage, then a vacuum foam dressing (or antibiotic bead pouch if significant segmental bone has been lost) is applied until definitive surgery is performed. 


\section{Skeletal stabilization}

In open fractures it is important to achieve provisional or definitive stability of the fractured bones as early as possible. This may protect the soft tissues around the zone of injury from further damage from fractured ends of bone, while restoring the length, alignment, rotation of the limb.

Limb length restoration may indirectly reduce the risk of infection by reducing the soft tissue dead space of the limb. Early skeletal stabilization may also facilitate the access to the surrounding soft tissues, thus facilitating their early recovery with an additional support for the relief of pain $(22,23)$.

Based on the evidence on the management of lower limb open fractures, it was clear that when the fracture is minimally contaminated or the fracture is uncomplicated eg: without a bone loss/multilevel fractures, if primary soft tissue cover can be achieved, definitive skeletal stability with internal fixation at the same time of initial wound debridement would be the better option. Otherwise an external fixation (eg: multiplanar/circular fixators) need to be carried out. Whenever the primary soft tissue cover is impossible the provisional stabilization with a spanning fixator can be achieved with the plan for early conversion to definitive stabilization with wound closure. Recommended time period for conversion would be 72 hours. Long leg plaster slabs or traction has been discouraged as modes of provisional stabilization (5).

\section{Wound closure}

In spite of inadequate RCT to decide on primary vs delayed secondary wound closure (24) many authors have emphasized the value of early closure unless there is heavy contamination as it may decrease infection rates, risk of re-operations, and the time for bony union of open tibial fractures $(5,25,26)$ but the exact time limit for soft tissue closure is yet to be determined.

Some authors have suggested immediate soft tissue cover at the time of definitive fixation of the bone e.g. Fix \& Flap concept (32) Gustillo type I, II and some of the IIIA cases would be suitable for primary closure (3) but this may not be practical unless there is a dedicated well experienced microsurgical team available throughout the day.
If wound is left opened in cases of heavy contamination so-called "second look" on the Zone of injury in 48 hours time after the initial debridement has been suggested by some authorities in order to assess the viability or further excision of soft tissues and to wash out any accumulated blood clots, tissue fluid coagulum or remaining foreign material (4).

Since Microsurgery is best performed before the vessels become friable and fibrosed which usually happen after 1 week, soft tissue reconstruction should be undertaken within 7 days from the injury (5). Bhattacharyya et al, agreed with this similar time limit as he observed the increased deep infection rate of open fractures when there was a delay more than 7 days for the soft tissue reconstruction even though the wounds were managed with negative pressure foam dressings (27).

\section{Negative pressure dressings}

Negative pressure dressings may reduce the rate of infection by reducing tissue desiccation as well as avoiding the pooling of serous fluid. It will also increase the local blood flow thus the speed of healing $(4,5,28)$ But the literature recommends that they should never be used as a substitute for meticulous surgical wound excision for coverage of exposed fractures with vascularised flaps (5).

\section{Local antibiotic therapy}

Local antibiotic delivery is commonly done for extensively contaminated wounds with an "antibiotic bead-pouch" construct formed with antibiotic powder and polymethyl methacrylate (PMMA) cement. These can be easily made in the operating room via recommended technique using form beads over 24-gauge wire with $3.6 \mathrm{~g}$ of tobramycin mixed with $40 \mathrm{~g}$ of PMMA cement $(5,29)$. The beads are counted and then placed into the wound and covered with an impermeable dressing. In use with systemic antibiotics this technique have shown $9 \%$ drop in infection rate of sever open fractures (30).

\section{Conclusions}

In spite of many arguments regarding the precise management of lower limb open fractures, it is well 
clear that early administration of appropriate antibiotics, planned surgical debridement, proper skeletal stabilization and early soft tissue cover will determine the outcome in any set up. It is mandatory to develop one's own multidisciplinary management protocol for the institution, based on current evidence, in order to achieve a favorable outcome in the management of lower limb open fractures. Such protocol and the knowledge on proper initial handling of an open fracture will be equally important for General surgeons as well as for Orthopedic surgeons since initial management of open fractures are left in the hands of both these groups.

\section{References}

1. Mauffrey C, Bailey JR, Bowles RJ, Price C, Hasson D, Hak DJ, Stahel PF. Acute management of open fractures: proposal of a new multidisciplinary algorithm. Orthopedics, 2012;35(10): 877-81.

2. Gustilo RB, Anderson JT. Prevention of infection in the treatment of one thousand and twenty five open fractures of long bones: retrospective and prospective analysis. $J$ Bone Joint Surg Am, 1976; 58(4):453-458.

3. Cross WW $3^{\text {rd }}$, Swiontkowski MF. Treatment principles in the management of open fractures. Indian J Orthop, 2008; 42(4): 377-86.

4. Hessmann M, Nork S, Sommer C, Twaddle B. Principles of management of open fractures. [Internet]. 2008 [cited 15 January 2015]. Available from: https://www2.aofoundation. org/wps/portal/surgery?showPage=diagnosis\&bone=Tibia \&segment $=$ Distal.

5. Nanchahal J, Nayagam S, Khan U, Moran C, Barrett S, Sanderson F, Pallister I. (2009) Standards for the management of open fractures of the lower limb. A Short Guide. BOA/BAPRAS. ISBN: 978-1-85315-911-4.

6. Patzakis MJ, Wilkins J, Moore TM. Considerations in reducing the infection rate in open tibial fractures. Clin Orthop Relat Res, 1983; 178: 36-41.

7. Gosselin RA, Roberts I, Gillespie WJ. Antibiotics for preventing infection in open limb fractures. Cochrane Database Syst Rev, 2004; 1: CD003764.

8. Patzakis MJ, Bains RS, Lee J. Prospective, randomized, double blind study comparing single agent antibiotic therapy, ciprofloxacin, to combination antibiotic therapy in open fracture wounds. J Orthop Trauma, 2000; 14: 529-33.
9. Bergman BR. Antibiotic prophylaxis in open and closed fractures: a controlled clinical trial. Acta Orthop Scand, 1982; 53(1): 57-62.

10. Braun R, Enzler MA, Rittmann WW. A double blind clinical trial of prophylactic cloxacillin in open fractures. J Orthop Trauma, 1987; 1(1): 12-7.

11. Carsenti-Etesse H, Doyon F, Desplaces N, et al. Epidemiology of bacterial infection during management of open leg fractures. Eur J Clin Microbiol Infect Dis, 1999; 18(5): 315-23.

12. Hoff W, Bonadies J, Cachecho R, et al. East practice management guidelines work group: update to practice management guidelines for prophylactic antibiotic use in open fractures. J Trauma. 2011; 70(3):751-4.

13. Patzakis MJ, Wilkins J. Factors influencing infection rate in open fracture wounds. Clin Orth Rela Res, 1989; 243: 36-40.

14. Templeman DC, Gulli B, Tsukayama DT, Gustilo RB. Update on the management of open fractures of the tibial shaft. Clin Orthop Relat Res, 1998; 350: 18-25.

15. Dellinger EP, Caplan ES, Weaver LD. Duration of preventive antibiotics administration for open extremity fractures. Arch Surg, 1988; 123(3): 333-9.

16. Zalavras CG, Patzakis MJ. Open fractures: Evaluation and management. JAm Acad Orthop Surg, 2003; 11: 212-9.

17. Robson MC, Duke WF, Krizek TJ. Rapid bacterial screening in the treatment of civilian wounds. J Surg Res, 1973; 14(5): 426-30.

18. Kindsfater K, Jonassen EA. Osteomyelitis in grade II and III open tibia fractures with late debridement. J Orthop Trauma, 1995;9(2): 121-7.

19. Penn-Barwell JG, Murray CK, Wenke JC. Early antibiotics and debridement independently reduce infection in an open fracture model. J Bone Joint Surg Br, 2012; 94(1): 107-12.

20. Bhandari M, Thompson K, Adili A, Shaughnessy SG. High and low pressure irrigation in contaminated wounds with exposed bone. Int J Surg Investig, 2000; 2: 179-82.

21. Anglen JO. Wound irrigation in musculoskeletal injury. JAm Acad Orthop Surg, 2001; 9: 219-26.

22. Merritt K. Factors increasing the risk of infection in patients with open fractures. J Trauma, 1988; 28: 823-7.

23. Worlock P, Slack R, Harvey L, Mawhinney R. The prevention of infection in open fractures: An experimental study of the effect of fracture stability. Injury, 1994; 25: 31-8. 
24. Eliya MC, Banda GW. Primary closure versus delayed closure for non bite traumatic wounds within 24 hours post injury. Cochrane Database Syst Rev, 2011; 9: CD00857

25. Gopal S, Majumder S, Batchelor AG, Knight SL, De Boer P, Smith RM. Fix and flap: The radical orthopaedic and plastic treatment of severe open fractures of the tibia. J Bone Joint Surg $B r, 2000 ; 82$ : 959-66.

26. Hertel R, Lambert SM, Muller S, Ballmer FT, Ganz R. On the timing of soft-tissue reconstruction for open fractures of the lower leg. Arch Orthop Trauma Surg, 1999; 119: 7-12.
27. Bhattacharyya T, Mehta P, Smith M, Pomahac B. Routine use of wound vacuum-assisted closure does not allow coverage delay for open tibia fractures. Plast Reconstr Surg, 2008; 121(4): 1263-6.

28. Ubbink DT, Westerbos SJ, Nelson EA, Vermeulen H. A systematic review of topical negative pressure therapy for acute and chronic wounds. BrJ Surg, 2008; 95(6): 685-92.

29. Zalavras CG, Patzakis MJ, Holtom P. Local antibiotic therapy in the treatment of open fractures and osteomyelitis. Clin Orthop Relat Res, 2004; 427: 86-93.

30. Ostermann PA, Seligson D, Henry SL. Local antibiotic therapy for severe open fractures. A review of 1085 consecutive cases. JBone Joint Surg Br, 1995; 77: 93-7. 